Article

\title{
Phenolic Content and Antimicrobial and Anti-Inflammatory Effects of Solidago virga-aurea, Phyllanthus niruri, Epilobium angustifolium, Peumus boldus, and Ononis spinosa Extracts
}

\author{
Claudio Ferrante 1(D), Annalisa Chiavaroli ${ }^{1}$, Paola Angelini ${ }^{2, *(D)}$, Roberto Venanzoni ${ }^{2}$, \\ Giancarlo Angeles Flores ${ }^{2}$, Luigi Brunetti ${ }^{1}$, Massimiliano Petrucci ${ }^{3}$, Matteo Politi ${ }^{1}$, \\ Luigi Menghini $^{1}\left(\mathbb{D}\right.$, Sheila Leone ${ }^{1}$, Lucia Recinella ${ }^{1}$, Gokhan Zengin ${ }^{4, *(\mathbb{D})}$, Gunes Ak ${ }^{4}$, \\ Massimo Di Mascio ${ }^{5}$, Francesco Bacchin ${ }^{5}$ and Giustino Orlando ${ }^{1}$ \\ 1 Department of Pharmacy, Università degli Studi “Gabriele d'Annunzio", via dei Vestini 31, \\ 66100 Chieti, Italy; claudio.ferrante@unich.it (C.F.); annalisa.chiavaroli@unich.it (A.C.); \\ luigi.brunetti@unich.it (L.B.); matteo.politi@unich.it (M.P.); luigi.menghini@unich.it (L.M.); \\ sheila.leone@unich.it (S.L.); lucia.recinella@unich.it (L.R.); giustino.orlando@unich.it (G.O.) \\ 2 Department of Chemistry, Biology and Biotechnology, University of Perugia, 06100 Perugia, Italy; \\ roberto.venanzoni@unipg.it (R.V.); giancarlo.angelesflores@studenti.unipg.it (G.A.F.) \\ 3 Omega Pharma Srl, Via Milano 129, 22063 Cantù (CO), Italy; m.petrucci@omegapharmasrl.com \\ 4 Department of Biology, Science Faculty, Selcuk Universtiy, Campus, Konya, 42130 Konya, Turkey; \\ akguneselcuk@gmail.com \\ 5 Veridia Italia Srl, via Raiale 285, 65100 Pescara, Italy; massimo.dimascio96@gmail.com (M.D.M.); \\ f.bacchin@veridia.it (F.B.) \\ * Correspondence: paola.angelini@unipg.it (P.A.); gokhanzengin@selcuk.edu.tr (G.Z.)
}

Received: 7 October 2020; Accepted: 4 November 2020; Published: 6 November 2020

\begin{abstract}
Prostatitis is an inflammatory condition that is related to multiple infectious agents, including bacteria and fungi. Traditional herbal extracts proved efficacious in controlling clinical symptoms associated with prostatitis. In this context, the aim of the present study was to explore the efficacy of extracts from Solidago virga-aurea, Ononis spinosa, Peumus boldus, Epilobium angustifolium, and Phyllanthus niruri against bacterial (Escherichia coli, Pseudomonas aeruginosa, Staphylococcus aureus, Bacillus cereus) and fungi strains (Candida albicans; C. tropicalis) involved in prostatitis. Additionally, anti-mycotic effects were tested against multiple species of dermatophytes (Trichophyton rubrum, T. tonsurans, T. erinacei, Arthroderma crocatum, A. quadrifidum, A. gypseum, A. currey, and A. insingulare). Antioxidant effects were also evaluated in isolated rat prostates challenged with lipopolysaccharide (LPS), and phytochemical analyses were conducted to identify and quantify selected phenolic compounds, in the extracts. Finally, a bioinformatics analysis was conducted to predict putative human and microbial enzymes targeted by extracts' phytocompounds and underlying the observed bio-pharmacological effects. The phytochemical analysis highlighted that rutin levels could be crucial for explaining the highest antibacterial activity of $P$. boldus extract, especially against E. coli and B. cereus. On the other hand, in the E. angustifolium extract, catechin concentration could partially explain the highest efficacy of this extract in reducing lipid peroxidation, in isolated rat prostates stimulated with LPS. Concluding, the results of the present study showed moderate antimicrobial and anti-inflammatory effects induced by water extracts of $S$. virga-aurea, P. boldus, E. angustifolium, P. niruri, and $O$. spinosa that could be related, at least partially, to the phenolic composition of the phytocomplex.
\end{abstract}

Keywords: Solidago virga-aurea; Phyllanthus niruri; Epilobium angustifolium; Peumus boldus; Ononis spinosa; antimicrobial; antioxidant/anti-inflammatory; bioinformatics 


\section{Introduction}

Prostatitis is an inflammatory condition that is related to multiple infectious agents, including bacteria and fungi [1-3]. The inflammatory pathways underlying prostatitis have been increasingly studied in recent years, and herbal extracts, especially in combination, have been revealed as a promising tool for the management of clinical symptoms related to the burden of inflammation/oxidative stress occurring in prostatitis [4]. Strictly related to this disorder, inflammation of the lower urinary tract (LUTS) is reported as the second most common human infectious disorder [5]. Currently, $\alpha$-blockers represent the first-choice treatment for LUTS in patients diagnosed with both prostatitis and benign prostate hyperplasia (BPH) [6]. On the other hand, traditional herbal extracts were efficacious in controlling the inflammatory component associated with these disorders [7-10], with the efficacy that could be improved through their pharmacological associations [11]. This is consistent, at least in part, with the scientific literature suggesting the benefits of the combination of herbal extracts, usually employed as food supplements, for treating chronic inflammatory diseases [12-16]. Increasing attention to alternative medications, including nutraceuticals and herbal preparations that could display a lower grade of side effects, has led to the exploration of extracts prepared from plants traditionally used by folk populations to manage inflammatory conditions [14]. These extracts, especially those prepared via traditional infusions or decoctions, could not only be effective and safe due to their long-term use, but also represent novel strategies for implementing local botanical chain productions [15,16].

Phyllanthus niruri is a traditional Ayurvedic remedy that has long been employed in a wide range of inflammatory disorders. It is also able to induce anti-proliferative effects on human prostate cancer PC3 cell lines [17]. Boldine, the main active principle of Peumus boldus, revealed to be effective in inducing apoptosis in human bladder cancer cells, as well [18]. Ononis spinosa is a folk remedy used in the treatment of urinary tract infections and stones [19]. Analogous traditional uses have been described for Solidago virga-aurea, although the scientific literature reported anti-proliferative effects, possibly related to the presence of terpene and phenolic compounds, in the phytocomplex $[20,21]$. Similarly, Epilobium angustifolium has been shown to be effective in preventing BPH [22] due to its richness in phenolic compounds [23].

In this context, the aim of the present study was to explore the antimicrobial and anti-inflammatory effects of water extracts from S. virga-aurea, O. spinosa, P. boldus, E. angustifolium, and P. niruri. Although the water solubility of plant secondary metabolites could be limited, previous studies of ours suggested the use of microwave- and ultrasound-assisted methods for improving phenol extraction that was paralleled by increased anti-inflammatory, antioxidant, and antimicrobial effects $[16,24,25]$. In the present study, the extracts' antimicrobial activity was tested against bacterial (Escherichia coli, Pseudomonas aeruginosa, Staphylococcus aureus, and Bacillus cereus) and fungi strains (Candida albicans, C. tropicalis) involved in prostatitis and LUTS [2,3,26-28]. Additionally, anti-mycotic activities were also tested against multiple species of dermatophytes (Trichophyton rubrum, T. tonsurans, T. erinacei, Arthroderma crocatum, A. quadrifidum, A. gypseum, A. Currey, and A. insingulare). This is consistent with the incidence of dermatophyte infections in patients suffering from urinary tract disorders, including renal failure and prostate adenocarcinoma [29-31]. Anti-inflammatory effects, in terms of reduction of prostaglandin production, were also evaluated in a preclinical model of prostatitis consisting of isolated rat prostate specimens challenged with lipopolysaccharide (LPS). The study also compared the efficacy of single extracts and their pharmacological association (Fluxonorm ${ }^{\circledR}$ ), and the obtained results supported the rationale for their use to treat clinical symptoms related to prostatitis and LUTS. In order to improve our knowledge about the mechanism of action of the studied herbal extracts, a fingerprint analysis via high-performance liquid chromatography coupled to ultraviolet and mass spectrometry (HPLC-UV-MS) was conducted to identify and quantify selected phenolic compounds, in the phytocomplex. Specifically, gallic acid, rutin, catechin, and epicatechin were selected considering their intrinsic antimicrobial and anti-inflammatory properties [32,33]. Finally, a bioinformatics analysis 
was also carried out to predict putative human and microbial enzymes targeted by the extracts' phytocompounds and underlying the observed bio-pharmacological effects.

\section{Materials and Methods}

\subsection{Plant Material}

Dry extracts of Phyllanthus niruri L. (family Phyllanthaceae), Ononis spinosa L. (family Fabaceae), Solidago virga-aurea L. (family Asteraceae), Peumus boldus Molina (family Monimiaceae), Epilobium angustifolium L. (family Onagraceae), and the registered trademark formula Fluxonorm ${ }^{\circledR}$ (O. spinosa/ S. virga-aurea/P. niruri/P. boldus/E. angustifolium 12.5:12.5:18.7:25.0:31.2), were provided as dried materials by OMEGA PHARMA Srl (Cantù, Italy). Before testing, extracts were rehydrated via ultrasound-assisted extraction at $60^{\circ} \mathrm{C}$ for one hour.

\subsection{Phytochemical Analysis}

P. niruri, E. angustifolium, P. boldus, S. virga-aurea, and O. spinosa extracts $(10 \mathrm{mg} / \mathrm{mL})$ were analyzed for phenol quantitative determination using a reversed-phase HPLC-UV-MS in gradient elution mode. The separation was conducted within $60 \mathrm{~min}$, starting from the conditions: water/acetonitrile: 93:7, $(v / v)$. The details about the gradient are listed in Table 1.

Table 1. Gradient elution.

\begin{tabular}{cccc}
\hline Time (min) & Flow & $\mathbf{\% A}$ & $\mathbf{\% B}$ \\
\hline $0-0.50$ & & 93 & 7 \\
25 & & 72 & 28 \\
30 & & 72 & 28 \\
38 & $1 \mathrm{~mL} / \mathrm{min}$ & 75 & 25 \\
45 & & 2 & 98 \\
48 & & 93 & 7 \\
58 & & 93 & 7 \\
\hline
\end{tabular}

The HPLC apparatus consisted of two PU-2080 PLUS chromatographic pumps, a DG-2080-54 line degasser, a mix-2080-32 mixer, a UV-2075 PLUS UV detector, an AS-2057 PLUS autosampler, and CO-2060 PLUS column thermostat, all made by JASCO (Tokyo, Japan). The used mass spectrometer was an Expression-L compact mass spectrometer (Advion, Ithaca, NY, USA). Integration was performed by JASCO ChromNAV2 chromatography software, and the separation was performed by gradient elution on an Agilent (Santa Clara, CA, USA) InfinityLab Poroshell 120 reverse phase column (C18, $150 \mathrm{~mm} \times 4.6 \mathrm{~mm}$ ID, $2.7 \mu \mathrm{m}$ ). The analytical conditions for the separation of gallic acid, catechin, epicatechin and rutin were in agreement with the study by Rodríguez-Delgado and colleagues [34]. Extracts were qualitatively analyzed with an Advion Expression-L compact mass spectrometer (MS) in negative ion mode. MS signal identification was realized through comparison with standard solutions and MS spectra present in the recognized Mass Bank Europe database (https://massbank.eu/MassBank/). Quantitative determination of phenolic compounds identified by MS analysis was performed via a UV detector at $240 \mathrm{~nm}$ wavelength. Quantification was done through 7 point calibration curves, with linearity coefficients $\left(R^{2}\right)>0.999$, in the concentration range of $2-140 \mu \mathrm{g} / \mathrm{mL}$. The area under the curve obtained from the HPLC chromatograms was used to quantify analyte concentration in the extracts. 
Protonic nuclear magnetic resonance $\left({ }^{1} \mathrm{H}-\mathrm{NMR}\right)$ analysis was conducted with a Varian $300 \mathrm{MHz}$ spectrometer using a standard proton pulse sequence (s2pul). Samples were prepared as follows: $10 \mathrm{mg} / \mathrm{mL}$ gallic acid and $50 \mathrm{mg} / \mathrm{mL}$ extract were sonicated in $\mathrm{CD}_{3} \mathrm{OD}$ for $30 \mathrm{~min}$ at room temperature. Next, $600 \mu \mathrm{L}$ of each sample was transferred into the NMR tube and analyzed with the following parameters: $1.706 \mathrm{~s}$ acquisition time, $4803.1 \mathrm{~Hz}$ width, and 64 scans.

\subsection{Artemia salina Lethality Test}

The cytotoxicity limit of the extracts in the range $0.1-20 \mathrm{mg} / \mathrm{mL}$ was evaluated through a lethality bioassay of the brine shrimp Artemia salina, as previously reported [16]. The experiments were carried out in triplicate.

\subsection{Cell Cultures and Viability Test}

The effects of the extracts $(100-500 \mu \mathrm{g} / \mathrm{mL})$ on myocyte C2C12 and prostate cancer PC3 cell viability were determined through the 3-(4,5-dimethylthiazol-2-yl)-2,5-diphenyltetrazolium bromide (MTT) test. The experimental conditions were fully described in our previous paper [35].

\subsection{Ex Vivo Pharmacological Study}

The protective effects of the extracts were investigated through an ex vivo model consisting of isolated prostate challenged with E. coli lipopolysaccharide (LPS) at $10 \mu \mathrm{g} / \mathrm{mL}$, as previously reported [9]. Prostates were collected from 24 Sprague Dawley rats (200-250 g). The study was approved by the Local Ethical Committee and the Italian Ministry of Health. The approval number of the study was the following: authorization N. F4738.N.XTQ, delivered for the period 11 November 2018- 11 November 2019. During the study, the prostate specimens were separately treated with the extracts of O. spinosa, S. virga-aurea, P. niruri, P. boldus, and E. angustifolium (100, 100, 150, 200, and $250 \mu \mathrm{g} / \mathrm{mL}$, respectively) or Fluxonorm ${ }^{\circledR}(800 \mu \mathrm{g} / \mathrm{mL})$. Afterward, the prostate tissue supernatants were assayed, as described below.

\subsection{8-Iso-PGF $2 \alpha$ and $P G E_{2}$ Radioimmunoassay}

The levels of 8-iso- $\mathrm{PGF}_{2 \alpha}$ and $\mathrm{PGE}_{2}$ in the supernatants were determined by radioimmunoassay (RIA). The detailed protocol was described in our previous study [36].

\subsection{Antibacterial and Antimycotic Activities}

The water extracts of P. niruri, O. spinosa, S. virga-aurea, P. boldus, and E. angustifolium were assayed for antibacterial activity against the following Gram-negative and Gram-positive strains: E. coli (ATCC 10536); E. coli (PeruMycA 2); E. coli (PeruMycA 3); P. aeruginosa (PeruMycA 5); S. typhy (PeruMycA 7); B. cereus (PeruMycA 4); B. subtilis (PeruMycA 6); S. aureus (ATCC 6538). Additionally, the same extracts were assayed for antimycotic effects against different Candida and dermatophyte species: C. tropicalis (DBVPG 6184); C. albicans (DBVPG 6379); C. parapsilosis (DBVPG 6551); C. albicans (DBVPG 6183); T. mentagrophytes (CCF 4823); T. tonsurans (CCF 4834); T. rubrum (CCF 4879); T. rubrum (CCF 4933); A. crocatum (CCF 5300); A. quadrifidum (CCF 5792); T. erinacei (CCF 5930); A. gypseum (CCF 6261); A. currey (CCF 5207); A. insingulare (CCF 5417). The antimicrobial activities of the aforementioned extracts were compared to reference drugs. To investigate the extracts effects on bacterial, Candida, and dermatophyte growth, the inhibitory activity was compared to ciprofloxacin, fluconazole and griseofulvin, respectively. The detailed protocols of the present antimicrobial assays have been fully described in recently published papers of ours $[37,38]$. 


\subsection{Bioinformatics}

Putative targets were identified according to the bioinformatic method recently described by Gu and colleagues [39]. Briefly, microbial and human proteins targeted by P. niruri, O. spinosa, S. virga-aurea, P. boldus, and E. angustifolium extracts were predicted using the bioinformatics platform STITCH (http://stitch.embl.de/cgi/network.pl). Docking calculations were conducted using AutoDock Vina PyRx 0.8 software. Crystal structures of target proteins were derived from the Protein Data Bank (PDB) with PDB IDs as follows: 1MJT (nitric oxide synthase (NOS) from S. aureus), 2FLQ (nitric oxide synthase (NOS) from B. cereus), and 1CX2 [cyclooxygenase-2 (COX-2)]. Discovery studio 2020 visualizer was employed to investigate the protein-ligand non-bonding interactions.

\subsection{Statistical Analysis}

The experimental data related to in vitro and ex vivo studies were analyzed through the analysis of variance (ANOVA) followed by the Newman-Keuls post hoc test. GraphPad Prism software was employed for the statistical analysis, while the software G*Power (v3.1.9.4, University of Kiel, Kiel, Germany) was used for calculating the animal number for the experiments, where $p<0.05$ was considered statistically significant.

\section{Results and Discussion}

Aiming to investigate the putative mechanism of action of the tested extracts, HPLC-UV-MS fingerprint analysis was carried out in order to measure the levels of selected phenolic compounds, namely gallic acid, catechin, epicatechin, and rutin, that play a master role in the antioxidant/anti-inflammatory response following herbal extract administration [40]. Specifically, the results of HPLC-UV-MS analysis depicted in Figures 1-5 show that the level of gallic acid is higher in P. niruri and E. angustifolium extracts, whereas P. boldus, O. spinosa and S. virga-aurea do not show a relevant amount of this compound. These data were also consistent with the ${ }^{1} \mathrm{H}-\mathrm{NMR}$ analyses (Figure 6), where the gallic acid protons signal (H-2, H-6) was detected at 7.048 ppm, mainly in P. niruri and E. angustifolium extracts, respectively. In the same extracts, the catechin fraction was also present at higher concentrations, compared to S. virga-aurea, P. boldus, and O. spinosa extracts, whereas $P$. boldus extract showed higher rutin concentration. In each figure, the concentration data were substantiated by related UV and MS chromatograms that highlighted a complete separation of the four measured phenolics within a $20 \mathrm{~min}$ HPLC run. Specifically, each analyte peak was qualitatively analyzed with MS detector in negative ion mode and the presence of gallic acid ( $\mathrm{m} / \mathrm{z}=169.1$; retention time $=3.00 \mathrm{~min})$, catechin $(\mathrm{m} / \mathrm{z}=289.3$; retention time $=8.95 \mathrm{~min})$, epicatechin $(\mathrm{m} / \mathrm{z}=289.3$; retention time $=12.20 \mathrm{~min})$, and rutin $(\mathrm{m} / \mathrm{z}=609.5$; retention time $=17.50 \mathrm{~min}$ ) was identified through comparison with related standards and with MS data collected by MassBank Europe (https://massbank.eu/MassBank/). According to the quantitative analysis conducted through the UV detector (set at $240 \mathrm{~nm}$ wavelength), E. angustifolium displayed the richest phenolic profile from both qualitative and quantitative points of view. This was consistent, albeit partially, with literature data suggesting the richness in phenolic compounds of E. angustifolium as a key factor influencing its efficacy in BHP [22,23].

\begin{tabular}{cccccc}
\hline & Peak $\mathrm{n}$. & $\mathrm{mg} / \mathrm{g}$ extract & S.D. & $\mathrm{m} / \mathrm{z}$ ratio & Rt (min) \\
\hline Gallic acid & 1 & 27.96 & 1.31 & 169.1 & 3.00 \\
\hline Catechin & 2 & 13.16 & 0.72 & 289.3 & 8.95 \\
\hline Epicatechin & 3 & 15.01 & 0.63 & 289.3 & 12.20 \\
\hline Rutin & 4 & 2.77 & 0.10 & 609.5 & 17.50 \\
\hline
\end{tabular}

Figure 1. Cont. 


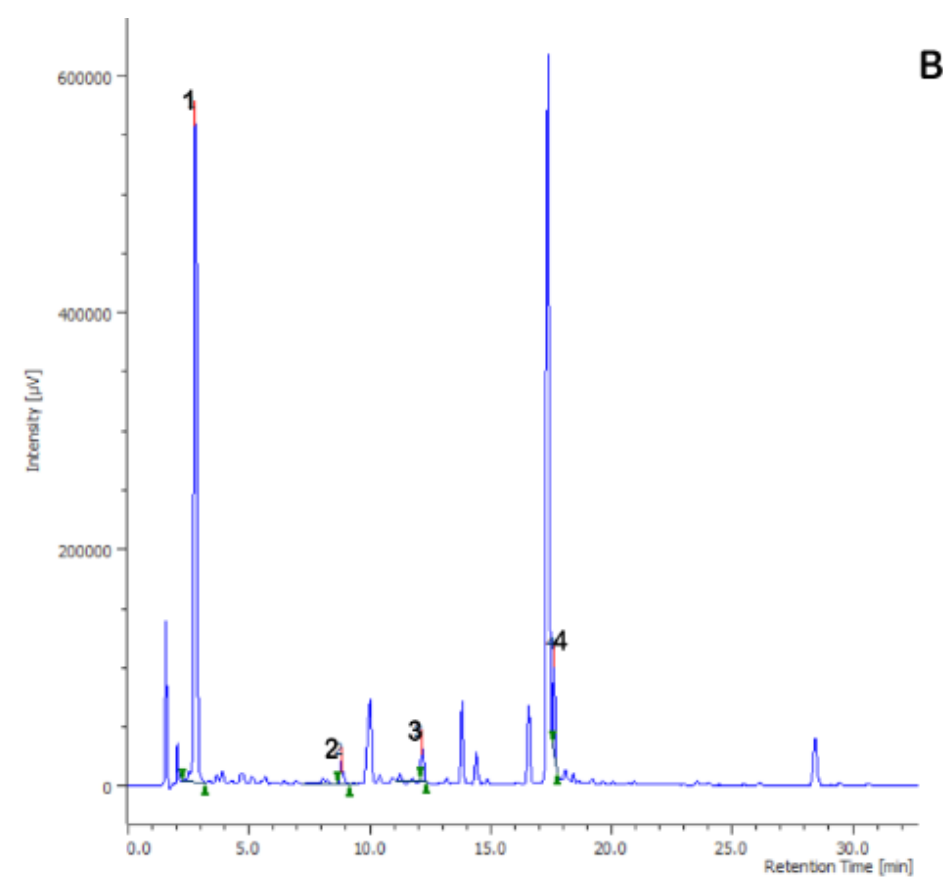

Figure 1. Quantitative analysis of Phyllanthus niruri water extract. (A): Levels (mg/g extract) of gallic acid (1), catechin (2), epicatechin (3), and rutin (4). (B): Chromatogram of selected phenolic compounds.

\begin{tabular}{cccccc}
\hline & Peak $\mathrm{n}$. & $\mathrm{mg} / \mathrm{g}$ extract & S.D. & $\mathrm{m} / \mathrm{z}$ ratio & Rt (min) \\
\hline Gallic acid & 1 & 1.17 & 0.05 & 169.1 & 3.00 \\
Catechin & 2 & 13.06 & 0.72 & 289.3 & 8.95 \\
Epicatechin & 3 & 1.40 & 0.06 & 289.3 & 12.20 \\
Rutin & 4 & 2.92 & 0.11 & 609.5 & 17.50 \\
\hline
\end{tabular}

A

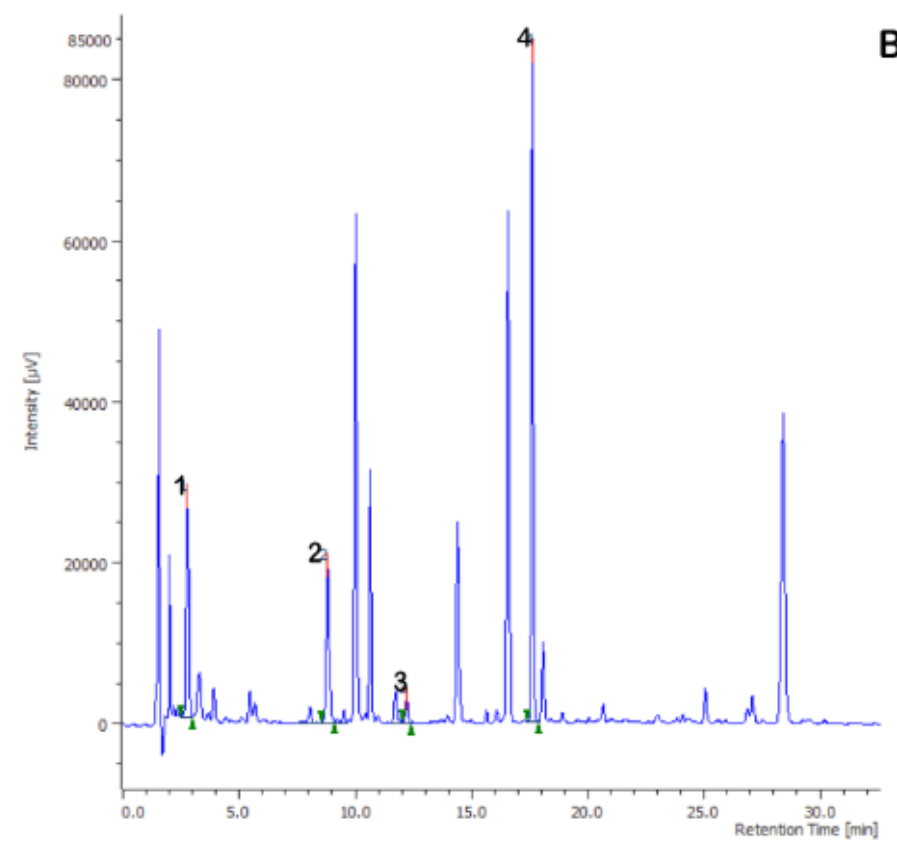

Figure 2. Quantitative analysis of Ononis spinosa water extract. (A): Levels (mg/g extract) of gallic acid (1), catechin (2), epicatechin (3), and rutin (4). (B): Chromatogram of selected phenolic compounds. 


\begin{tabular}{cccccc}
\hline & Peak n. & $\mathrm{mg} / \mathrm{g}$ extract & S.D. & $\mathrm{m} / \mathrm{z}$ ratio & Rt (min) \\
\hline Gallic acid & 1 & 11.73 & 0.55 & 169.1 & 3.00 \\
Catechin & 2 & 69.12 & 3.80 & 289.3 & 8.95 \\
Epicatechin & 3 & 55.59 & 2.33 & 289.3 & 12.20 \\
Rutin & 4 & 2.37 & 0.09 & 609.5 & 17.50 \\
\hline
\end{tabular}

A

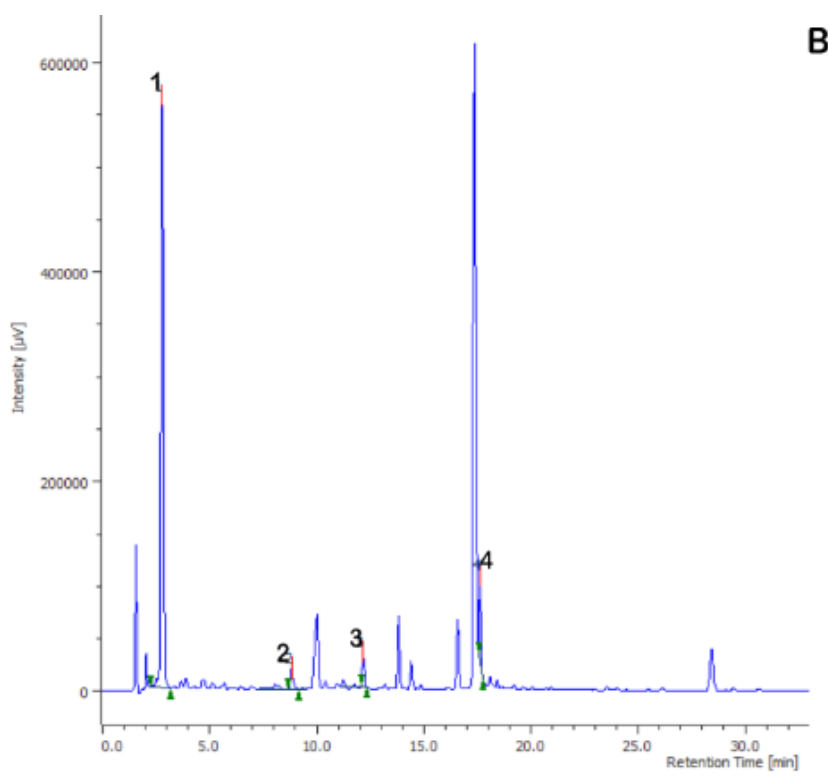

Figure 3. Quantitative analysis of Epilobium angustifolium water extract. (A): Levels (mg/g extract) of gallic acid (1), catechin (2), epicatechin (3), and rutin (4). (B): Chromatogram of selected phenolic compounds.

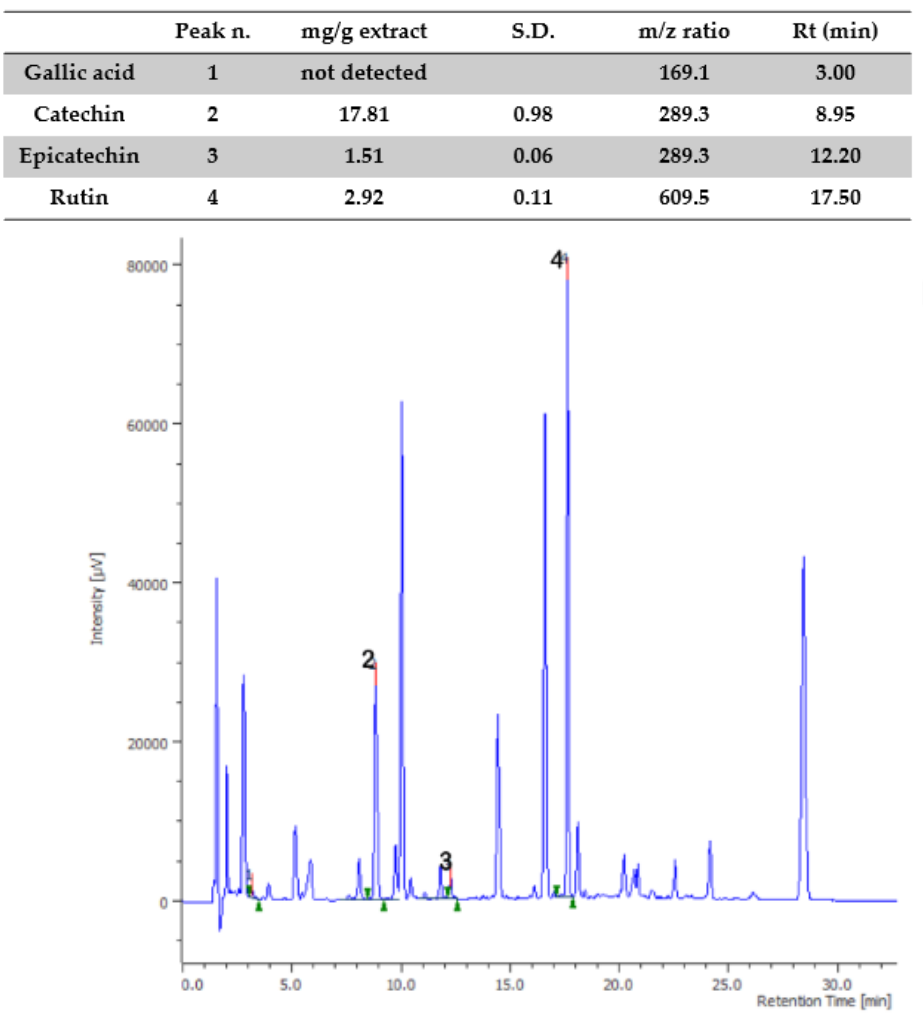

Figure 4. Quantitative analysis of Solidago virga-aurea water extract. (A): Levels (mg/g extract) of gallic acid (1), catechin (2), epicatechin (3), and rutin (4). (B): Chromatogram of selected phenolic compounds. 


\begin{tabular}{cccccc}
\hline & Peak $\mathrm{n}$. & $\mathrm{mg} / \mathrm{g}$ extract & S.D. & $\mathrm{m} / \mathrm{z}$ ratio & Rt (min) \\
\hline Gallic acid & 1 & not detected & & 169.1 & 3.00 \\
Catechin & 2 & 14.87 & 0.82 & 289.3 & 8.95 \\
Epicatechin & 3 & 2.13 & 0.09 & 289.3 & 12.20 \\
\hline Rutin & 4 & 3.31 & 0.12 & 609.5 & 17.50 \\
\hline
\end{tabular}

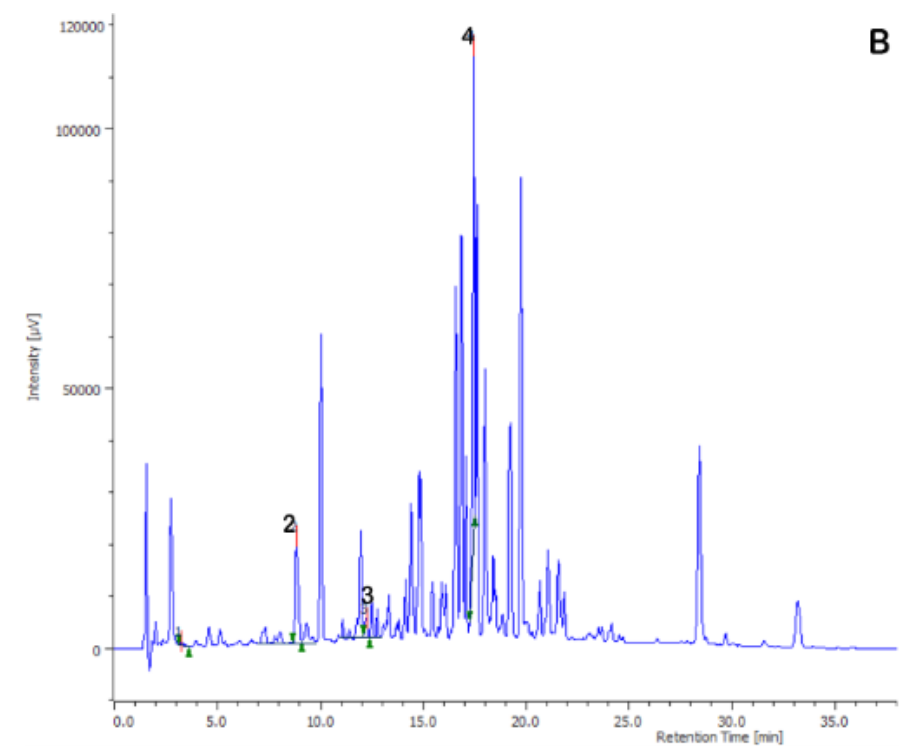

Figure 5. Quantitative analysis of Peumus boldus water extract. (A): Levels (mg/g extract) of gallic acid (1), catechin (2), epicatechin (3), and rutin (4). (B): Chromatogram of selected phenolic compounds.

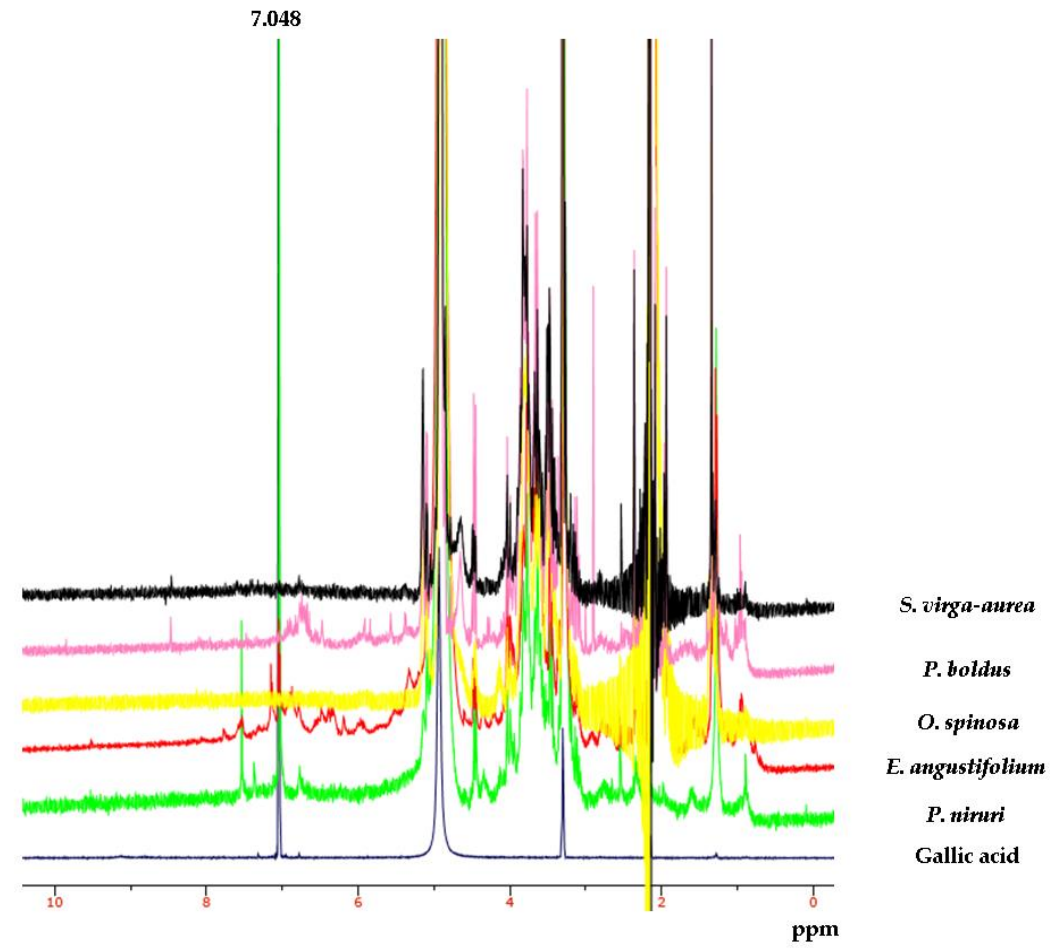

Figure 6. From top to bottom, ${ }^{1} \mathrm{H}-\mathrm{NMR}$ spectra of Solidago virga-aurea (black), Peumus boldus (pink), Ononis spinosa (yellow), Epilobium angustifolium (red), and Phyllanthus niruri (green) extracts and gallic acid standard solution (blue). The gallic acid protons signal (H-2, H-6) is visible at $7.048 \mathrm{ppm}$ and is detected in P. niruri and E. angustifolium extracts. 


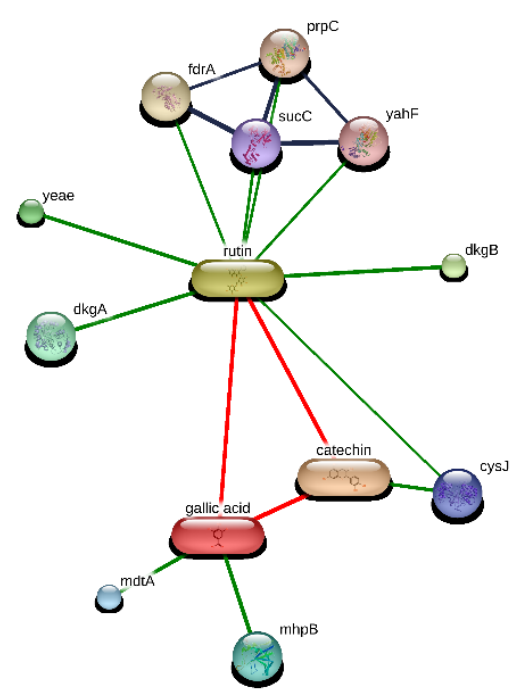

(A)

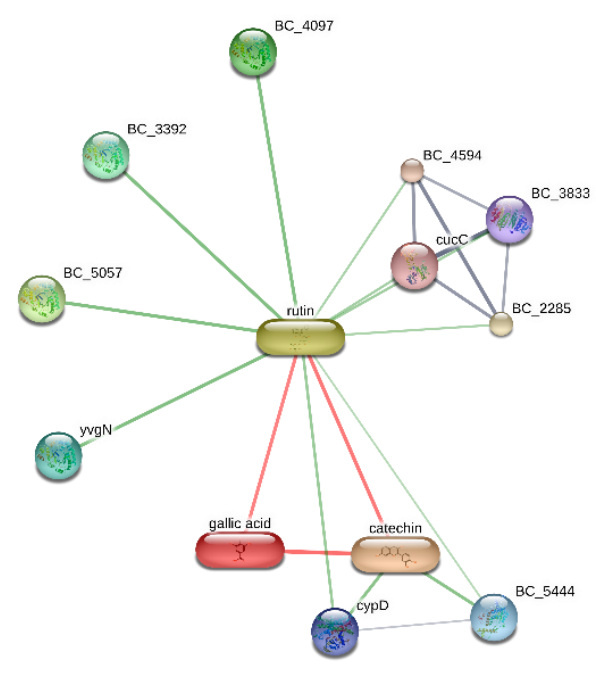

(B)

Figure 7. Targets-components analysis conducted on the STITCH bioinformatics platform for unraveling putative interactions between extracts' phytochemicals and putative proteins involved in the oxidative metabolism of E. coli (subfigure (A)) and B. cereus (subfigure (B)). In both subfigures, the prominent position of rutin is highlighted with regards to its putative interactions with bacterial enzymes, among which is $B$. cereus nitric oxide synthase (BC_44).

The extracts were also assayed for the brine shrimp (A. salina) lethality test to evaluate the biocompatibility limit in the standard range $(0.01-10 \mathrm{mg} / \mathrm{mL})$ [41]. The brine shrimp test yielded $\mathrm{LC}_{50}$ values $>10 \mathrm{mg} / \mathrm{mL}$ that were indicatory for choosing a concentration limit at least ten-fold lower than $\mathrm{LC}_{50}$ for the following bio-pharmacological tests [16]. In this regard, the extracts were assayed for antimicrobial activity against multiple bacterial and fungi strains (Tables 2-4), including Candida and dermatophyte species, that could be involved in infectious disorders of the urinary tract [28-31]. It is of noteworthy interest that most of the tested extracts showed bacteriostatic and mycostatic effects at concentrations much lower than $\mathrm{LC}_{50}$ values calculated via the brine shrimp test. In the present multidirectional study, the inhibitory effects of tested extracts on bacterial and fungi strains were expressed as $\mu \mathrm{g} / \mathrm{mL}$ in order to better compare the concentrations of the extracts 
active as antimicrobials with those active as anti-inflammatory/antioxidant agents $[16,37,38]$. On the other hand, multiple studies suggest the use of arbitrary units to express the antimicrobial activity of herbal extracts as well [42-44]. The spectrum of antimicrobial activity seems to be paralleled, at least partially, by the extract qualitative composition. In this regard, E. angustifolium was effective against a larger number of microbial species compared to the other tested extracts that displayed lower levels of catechins. The quantitative HPLC analysis also suggested that E. angustifolium could have a higher content of total phenols, thus substantiating the wider spectrum of antimycotic activity [16]. Nevertheless, P. boldus was the most active as antibacterial agent against both E. coli and B. cereus. It is sensitive to note that $P$. boldus displayed the highest rutin concentration that could be crucial for the highest antibacterial activity against these strains. This hypothesis seemed to be validated by the bioinformatics analysis conducted through the STITCH platform that highlighted a prominent position for rutin in the scenario of putative interactions between identified phytocompounds and bacterial proteins involved in oxidative metabolism (Figure 7A,B). Regarding the B. cereus, a further docking analysis was conducted to calculate the affinity of rutin towards $B$. cereus nitric oxide synthase (BC_44). Intriguingly, the docking run yielded an affinity constant $(\mathrm{Ki})$ in the sub-micromolar range (Figure 8). This result adds to our recent observation about the putative interactions between BC_44 and resveratrol [37]. Nevertheless, the inhibitory effect induced by rutin on B. cereus occurred at concentrations higher than $250 \mu \mathrm{g} / \mathrm{mL}$, thus excluding the interaction of this flavonoid with BC_44 as a key event underlying the antimicrobial effect induced by P. boldus. In this regard, we hypothesize that total phenolic compound content could be involved in the antibacterial activity [16], as also suggested by the P. boldus HPLC-UV-MS chromatogram and ${ }^{1} \mathrm{H}-\mathrm{NMR}$ spectrum showing numerous signals related to unidentified phenolic compounds present in this extract.
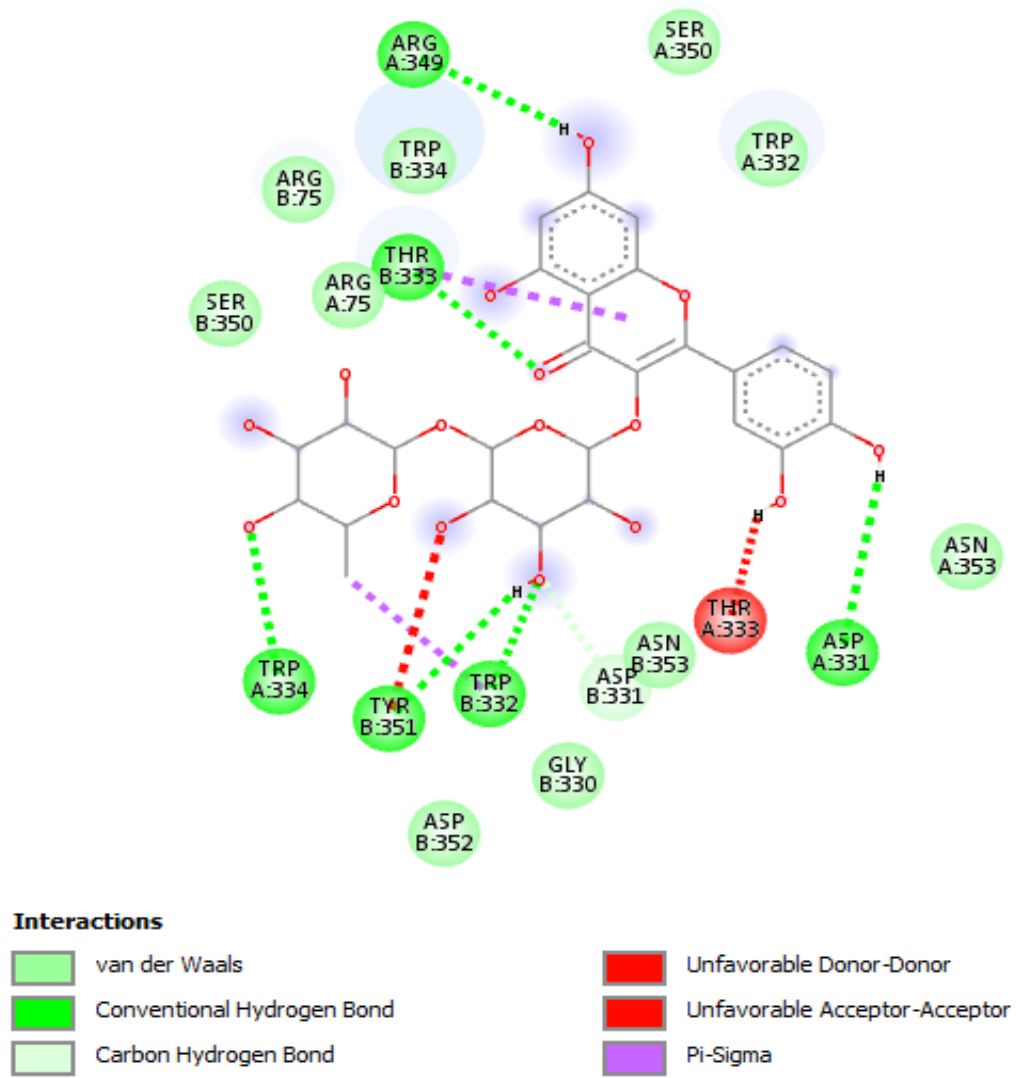

Figure 8. Putative interactions between rutin and B. cereus nitric oxide synthase (BC_5444; PDB: 2FLQ). Free energy of binding $(\Delta \mathrm{G})$ and affinity $(\mathrm{Ki})$ are $-8.9 \mathrm{kcal} / \mathrm{mol}$ and $0.3 \mu \mathrm{M}$, respectively. 
Table 2. Minimal inhibitory concentrations (MICs) of plant extracts against dermatophytes strains.

\begin{tabular}{|c|c|c|c|c|c|c|}
\hline \multirow[b]{2}{*}{ Dermatophyte Strains (ID) } & \multicolumn{6}{|c|}{ Minimum Inhibitory Concentration (MIC) * } \\
\hline & $\begin{array}{l}\text { P. boldus } \\
(\mu \mathrm{g} / \mathrm{mL})\end{array}$ & $\begin{array}{c}\text { E. angustifolium } \\
(\mu \mathrm{g} / \mathrm{mL})\end{array}$ & $\begin{array}{l}\text { O. spinosa } \\
(\mu \mathrm{g} / \mathrm{mL})\end{array}$ & $\begin{array}{l}\text { P. niruri } \\
(\mu \mathrm{g} / \mathrm{mL})\end{array}$ & $\begin{array}{l}\text { S. virga-aurea } \\
(\mu \mathrm{g} / \mathrm{mL})\end{array}$ & $\begin{array}{c}\text { Griseofulvin } \\
(\mu \mathrm{g} / \mathrm{mL})\end{array}$ \\
\hline T. mentagrophytes (CCF 4823) & $78.74(62.5-125)$ & $99.21(62.25-125$ & $>250$ & $198.42(125-250)$ & $>250$ & $2.52(2-4)$ \\
\hline T. tonsurans (CCF 4834) & $9.84(7.81-15.62)$ & $12.4(7.81-15.62)$ & $78.74(62.5-125)$ & $49.60(31.25-62.5)$ & $49.6(31.25-62.5)$ & $0.198(0.125-0.25)$ \\
\hline T. rubrum (CCF 4879) & $>250$ & $78.74(62.5-125)$ & $99.21(62.5-125)$ & $78.74(62.5-125)$ & $99.21(62.5-125)$ & $3.175(2-4)$ \\
\hline T. rubrum (CCF 4933) & $24.80(15.62-31.25)$ & $24.80(15.62-31.25)$ & $49.6(31.25-62.5)$ & $49.6(31.25-62.5)$ & $99.21(62.5-125)$ & $1.26(1-2)$ \\
\hline A. crocatum (CCF 5300) & $19.68(15.62-31.25)$ & $19.68(15.62-31.25)$ & $24.80(15.62-31.25)$ & $39.37(31.25-62.5)$ & $78.74(62.5-125)$ & $>8$ \\
\hline A. quadrifidum (CCF 5792) & $39.37(31.25-62.25)$ & $78.74(62.5-125)$ & $198.42(125-250)$ & $>250$ & $198.42(125-250)$ & $>8$ \\
\hline T. erinacei (CCF 5930) & $>250$ & $198.42(125-250)$ & $>250$ & $>250$ & $>250$ & $3.174(2-4)$ \\
\hline A. gypseum (CCF 6261) & $157.49(125-250)$ & $157.49(125-250)$ & $>250$ & $>250$ & $>250$ & $1.587(1-2)$ \\
\hline A. currey (CCF 5207) & $24.80(15.62-31.25)$ & $39.37(31.25-62.5)$ & $78.74(62.5-125)$ & $49.6(31.25-62.5)$ & $78.74(62.5-125)$ & $>8$ \\
\hline A. insingulare (CCF 5417) & $39.37(31.25-62.25)$ & $49.61(31.25-62.5)$ & $99.21(62.5-125)$ & $78.74(62.5-125)$ & $99.21(62.5-125)$ & $>8$ \\
\hline
\end{tabular}

${ }^{*}$ MIC values are reported as geometric means of three independent replicates $(n=3)$. MIC range concentrations are reported within brackets.

Table 3. Minimal inhibitory concentrations (MICs) of plant extracts against yeasts strains.

\begin{tabular}{|c|c|c|c|c|c|c|}
\hline \multirow[b]{2}{*}{ Yeast Strains (ID) } & \multicolumn{6}{|c|}{ Minimum Inhibitory Concentration (MIC) * } \\
\hline & $\begin{array}{l}\text { P. boldus } \\
(\mu \mathrm{g} / \mathrm{mL})\end{array}$ & $\begin{array}{c}\text { E. angustifolium } \\
(\mu \mathrm{g} / \mathrm{mL})\end{array}$ & $\begin{array}{l}\text { O. spinosa } \\
(\mu \mathrm{g} / \mathrm{mL})\end{array}$ & $\begin{array}{l}\text { P. niruri } \\
(\mu \mathrm{g} / \mathrm{mL})\end{array}$ & $\begin{array}{l}\text { S. virga-aurea } \\
(\mu \mathrm{g} / \mathrm{mL})\end{array}$ & $\begin{array}{c}\text { Fluconazole } \\
(\mu \mathrm{g} / \mathrm{mL})\end{array}$ \\
\hline C. tropicalis (DBVPG 6184) & $157.49(125-250)$ & $49.60(31.25-62.5)$ & $78.74(62.5-125)$ & $99.21(62.5-125)$ & $49.60(31.25-62.5)$ & 2 \\
\hline C. albicans (DBVPG 6379) & $>250$ & $198.42(125-250)$ & $198.42(125-250)$ & $(\geq 250)$ & $>250$ & 1 \\
\hline C. parapsilosis (DBVPG 6551) & $198.42(125-250)$ & $(\geq 250)$ & $>250$ & $>250$ & $198.42(125-250)$ & 4 \\
\hline C. albicans (DBVPG 6183) & $99.21(62.5-125)$ & $157.49(125-250)$ & $>250$ & $>250$ & $>250$ & 2 \\
\hline
\end{tabular}

* MIC values are reported as geometric means of three independent replicates $(n=3)$. MIC range concentrations are reported within brackets. 
Table 4. Minimal inhibitory concentrations (MICs) of plant extracts against bacterial strains.

\begin{tabular}{|c|c|c|c|c|c|c|}
\hline \multirow[b]{2}{*}{ Bacterial Strains (ID) } & \multicolumn{6}{|c|}{ Minimum Inhibitory Concentration (MIC) * } \\
\hline & $\begin{array}{l}\text { P. boldus } \\
(\mu \mathrm{g} / \mathrm{mL})\end{array}$ & $\begin{array}{c}\text { E. angustifolium } \\
(\mu \mathrm{g} / \mathrm{mL})\end{array}$ & $\begin{array}{c}\text { O. spinosa } \\
(\mu \mathrm{g} / \mathrm{mL})\end{array}$ & $\begin{array}{l}\text { P. niruri } \\
(\mu \mathrm{g} / \mathrm{mL})\end{array}$ & $\begin{array}{l}\text { S. virga-aurea } \\
(\mu \mathrm{g} / \mathrm{mL})\end{array}$ & $\begin{array}{c}\text { Ciprofloxacin } \\
(\mu \mathrm{g} / \mathrm{mL})\end{array}$ \\
\hline \multicolumn{7}{|l|}{ Gram- } \\
\hline E. coli (ATCC 10536) & $24.80(7.81-15.625)$ & $78.74(62.5-125)$ & $49.60(31.25-62.5)$ & $39.37(31.25-62.5)$ & $78.74(62.5-125)$ & $<0.12$ \\
\hline E. coli (PeruMycA 2) & $39.37(31.25-62.5)$ & $157.49(125-250)$ & $99.21(62.5-125)$ & $49.60(31.25-62.5)$ & $49.60(31.25-62.5)$ & $1.23(1.95-0.98)$ \\
\hline E. coli (PeruMycA 3) & $99.21(62.5-125)$ & $198.42(125-250)$ & $157.49(125-250)$ & $(\geq 250)$ & $>250$ & $0.62(0.98-0.49)$ \\
\hline P. aeruginosa (PeruMycA 5) & $78.74(62.5-125)$ & $99.21(62.5-125)$ & $49.60(31.25-62.5)$ & $24.8(15.62-31.25)$ & $39.37(31.25-62.5)$ & $1.23(1.95-0.98)$ \\
\hline S. typhy (PeruMycA 7) & $157.49(125-250)$ & $198.42(125-250)$ & $(\geq 250)$ & $198.42(125-250)$ & $(\geq 250)$ & $0.38(0.49-0.24)$ \\
\hline \multicolumn{7}{|l|}{ Gram+ } \\
\hline B. cereus (PeruMycA 4) & $78.74(62.5-125)$ & $99.21(62.5-125)$ & $198.42(125-250)$ & $49.60(31.25-62.5)$ & $78.74(62.5-125)$ & $<0.12$ \\
\hline B. subtilis (PeruMycA 6) & $157.49(125-250)$ & $198.42(125-250)$ & $(\geq 250)$ & $99.21(62.5-125)$ & $157.49(125-250)$ & $<0.12$ \\
\hline S. aureus (ATCC 6538) & $198.42(125-250)$ & $198.42(125-250)$ & $99.21(62.5-125)$ & $78.74(62.5-125)$ & $99.21(62.5-125)$ & $0.62(0.98-0.49)$ \\
\hline
\end{tabular}

${ }^{*}$ MIC values are reported as geometric means of three independent replicates $(n=3)$. MIC range concentrations are reported within brackets. 
The different pattern of antimicrobial activity also supports the rationale for the pharmacological association of tested extracts in order to improve their efficacy. In this regard, in vitro tests were conducted on the non-tumoral cell line $\mathrm{C} 2 \mathrm{C} 12$ to expand our comprehension about the intrinsic tolerability and protective effects of the extracts employed as both single treatment and pharmacological associations (Fluxonorm ${ }^{\circledR}$ ). Specifically, MTT assay was carried out, and extracts were tested in the concentration range $100-500 \mu \mathrm{g} / \mathrm{mL}$, whereas the Fluxonorm ${ }^{\circledR}$ formula was assayed in the range from $800-1600 \mu \mathrm{g} / \mathrm{mL}$. The null effect on the cell viability after challenging the cells with the extracts (Figure 9) further confirmed the biocompatibility of the selected water extracts. The pharmacological association Fluxonorm ${ }^{\circledR}$, which was the resulting algebraic sum of the aforementioned extracts used as single ingredients in the ratio reported in Section 2.1, was completely tolerated at the lowest tested concentration $(800 \mu \mathrm{g} / \mathrm{mL})$. By contrast, the cell viability tended to decrease under the biocompatibility limit $(80 \%)$ at the highest formula concentration $(1600 \mu \mathrm{g} / \mathrm{mL})$. It is rational to hypothesize that the reduced cell viability at the highest tested concentration could be related to the paradoxical phenolic compound-induced oxidative stress that often occurs at elevated concentrations [45,46]. Conversely, under the limit of biocompatibility, the single extracts and Fluxonorm ${ }^{\circledR}$ were able to contrast the burden of oxidative stress and inflammation in isolated rat prostate specimens challenged with LPS, an ex vivo model of prostatitis $[11,47]$. All extracts were able to completely blunt the LPS-induced level of both $\mathrm{PGE}_{2}$ and 8-iso- $\mathrm{PGF}_{2 \alpha}$ (Figure 10A,B). $\mathrm{PGE}_{2}$ is the main prostanoid synthesized by cyclo-oxygenase (COX)-2 in inflammatory conditions [48], and up-regulated levels of $\mathrm{PGE}_{2}$ are found in prostate inflammation and cancer $[49,50]$. While, 8 -iso-PGF $2 \alpha$ is an isomer of classical prostaglandins that is principally produced by oxidative stress-mediated pathways, including reactive oxygen/nitrogen species (ROS/RNS), that could cause disruptive peroxidation reactions on cellular substrates, such as proteins, lipids and nucleic acids [51]. In this regard, 8-iso- $\mathrm{PGF}_{2 \alpha}$ deriving from ROS/RNS peroxidation of membrane arachidonic acid represents a diagnostic biomarker for evaluating lipid peroxidation in vivo [52]. On the other hand, a paradoxically reduced level of 8-iso- PGF $_{2 \alpha}$ has been observed in superficial bladder cancer, possibly related to the putative vasoconstrictor role of this prostanoid [53]. Currently, the reduced levels of both $\mathrm{PGE}_{2}$ and 8-iso- $\mathrm{PGF}_{2 \alpha}$ following extract treatment are consistent with the qualitative and quantitative profile of the analyzed phytochemicals. However, the best pharmacological profile was showed by E. angustifolium, which influenced the antioxidant/anti-inflammatory role of Fluxonorm ${ }^{\circledR}$ the most. This is probably related to its content in catechin and epicatechin, which are known to behave as COX-2 inhibitors [54]. It is sensitive to highlight the clinical study carried out by Micali and colleagues [55], which evidenced a significant reduction in prostate-specific antigen following green tea catechin administration, thus suggesting its potential efficacy in treating/preventing inflammatory prostate diseases. Furthermore, the antiproliferative effects of green tea deriving catechins were demonstrated in multiple cancer cell lines, including prostate cancer LNCaP cells [56]. The pivotal role of catechin in the anti-inflammatory response related to extract treatment was also indicated by bioinformatics analysis (Figure 11). In this regard, besides COX-2, different pro-inflammatory proteins were predicted to be targeted by catechin, including inducible nitric oxide synthase (iNOS). Additionally, the sub-micromolar/micromolar affinity of catechin towards COX-2 and iNOS (Figure 12A,B) agreed with catechin levels in all tested extracts. The highest efficacy of E. angustifolium in contrasting the burden of oxidative stress/inflammation in isolate prostate specimens was consistent with the recent findings by Deng and colleagues (2019), as well as the capability of E. angustifolium extract to counteract the oxidative stress in male rats subcutaneously injected with testosterone in order to induce BHP [22]. The same authors also suggested that phytocomplex phenolic compounds could be crucial for substantiating the antioxidant/anti-inflammatory effects of E. angustifolium in the prostate. Finally, prostate cancer PC3 cells were treated with single extracts and Fluxonorm ${ }^{\circledR}$. Specifically, E. angustifolium, P. niruri, P. boldus, and Fluxonorm ${ }^{\circledR}$ showed similar antiproliferative effects (Figure 13) that could be related, at least partially, to multiple anti-inflammatory and antioxidant mechanisms [57-59]. In this context, it is sensitive to hypothesize that phenolic compounds present in the tested extracts could be responsible for the observed antiproliferative effects. 
However, these effects agree only partially with the levels of selected phenolic compounds measured via HPLC-UV-MS analyses. The chromatograms of the same analyses, but also the NMR spectra, suggest the presence of other unidentified phenolic compounds that could be crucial for the observed bio-pharmacological effects.

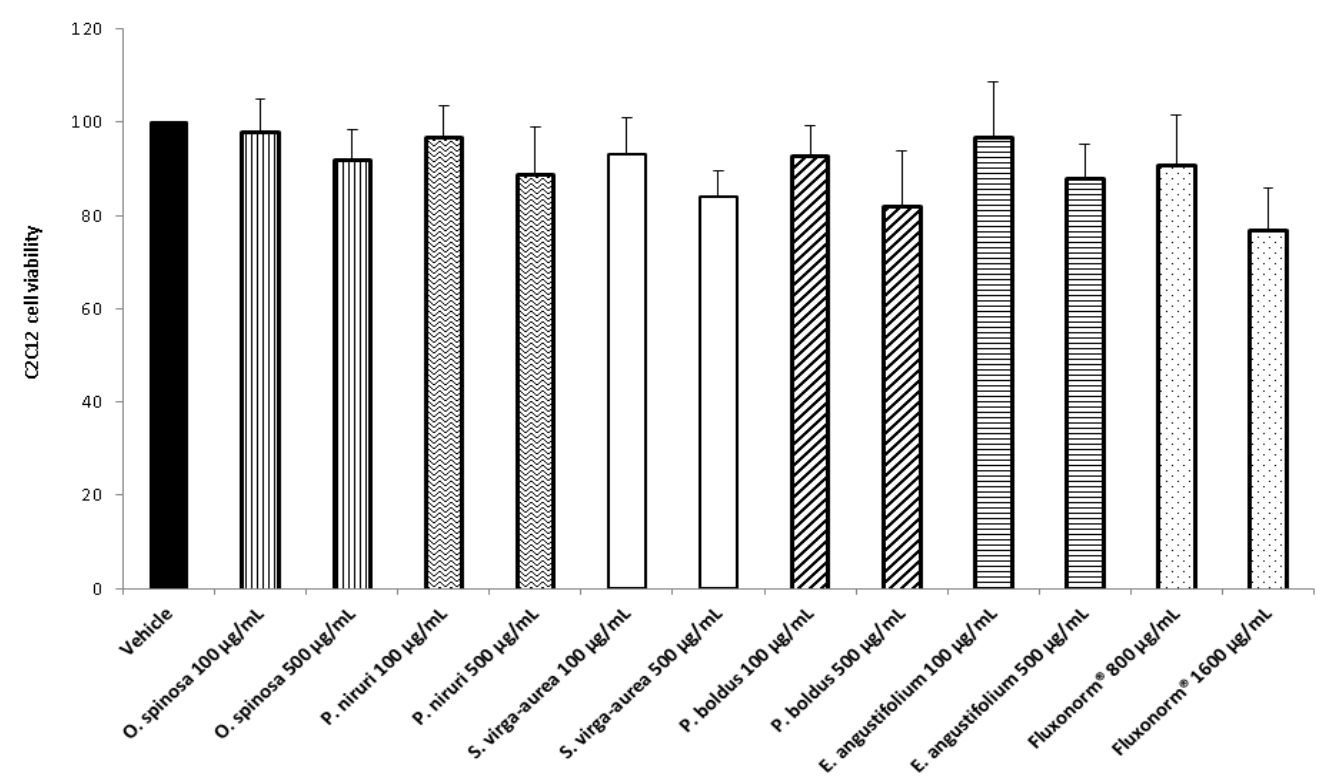

Figure 9. Effect of Phyllanthus niruri, Ononis spinosa, Solidago virga-aurea, Peumus boldus, and Epilobium angustifolium extracts $(100-500 \mu \mathrm{g} / \mathrm{mL})$ and Fluxonorm ${ }^{\circledR}(800-1600 \mu \mathrm{g} / \mathrm{mL})$ on myocyte C2C12 cell viability (MTT test).

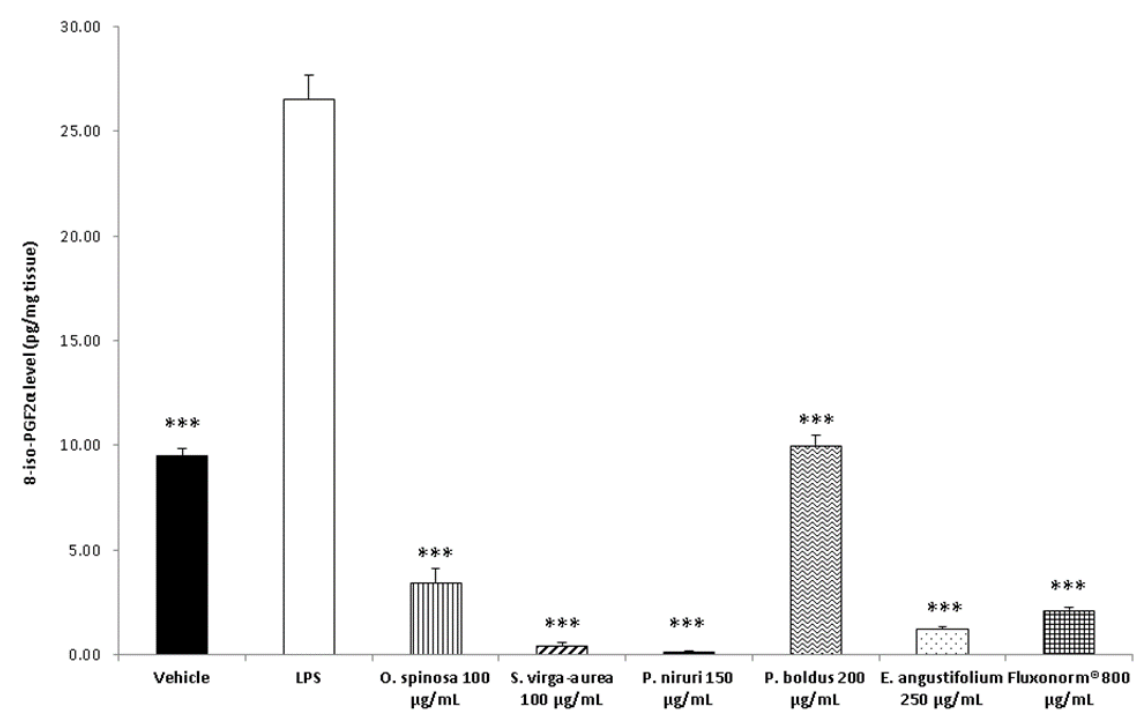

(A)

Figure 10. Cont. 


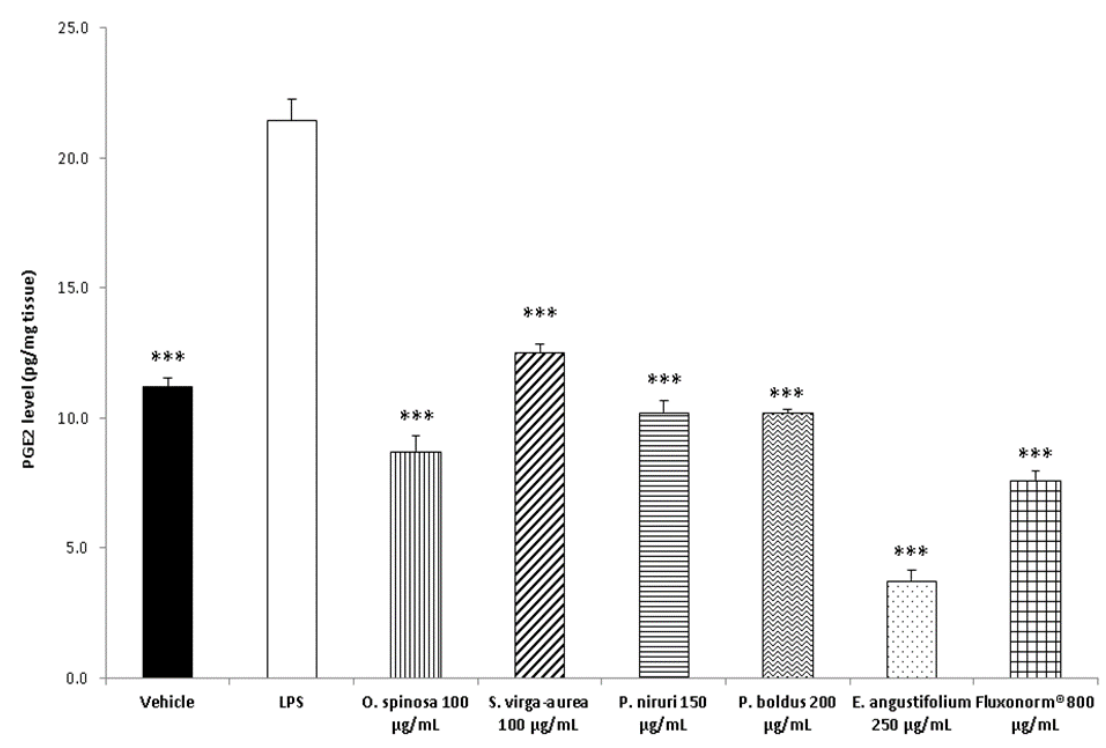

(B)

Figure 10. (A) Effect of extracts of Phyllanthus niruri $100 \mu \mathrm{g} / \mathrm{mL}$, Ononis spinosa $100 \mu \mathrm{g} / \mathrm{mL}$, Solidago virga-aurea $150 \mu \mathrm{g} / \mathrm{mL}$, Peumus boldus $200 \mu \mathrm{g} / \mathrm{mL}$, and Epilobium angustifolium $250 \mu \mathrm{g} / \mathrm{mL}$ water extracts and Fluxonorm ${ }^{\circledR} 800 \mu \mathrm{g} / \mathrm{mL}$ on 8 -iso-prostaglandin $(\mathrm{PG}) \mathrm{F}_{2 \alpha}$ production in isolated rat prostates challenged with E. coli lipopolysaccharide (LPS: $10 \mu \mathrm{g} / \mathrm{mL}$ ). ANOVA, $p<0.0001$, post-hoc ${ }^{* * *} p<0.001$ vs. LPS group. (B) Effect of water extracts of P. niruri $100 \mu \mathrm{g} / \mathrm{mL}$, O. spinosa $100 \mu \mathrm{g} / \mathrm{mL}$, S. virga-aurea $150 \mu \mathrm{g} / \mathrm{mL}$, P. boldus $200 \mu \mathrm{g} / \mathrm{mL}$, and E. angustifolium $250 \mu \mathrm{g} / \mathrm{mL}$ water extracts and Fluxonorm ${ }^{\circledR}$ $800 \mu \mathrm{g} / \mathrm{mL}$ on prostaglandin (PG)E2 production in isolated rat prostate challenged with E. coli lipopolysaccharide (LPS: $10 \mu \mathrm{g} / \mathrm{mL}$ ). ANOVA, $p<0.0001$, post-hoc ${ }^{* * *} p<0.001 \mathrm{vs}$. LPS group.

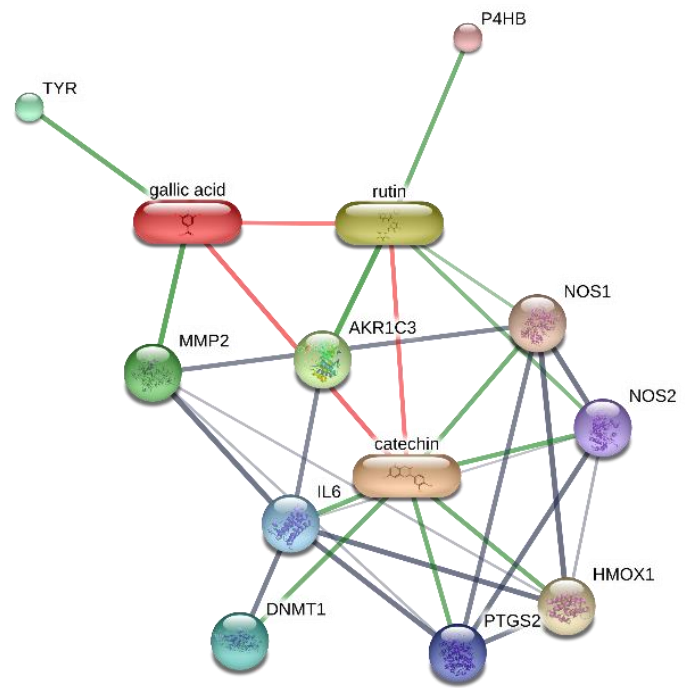

Figure 11. Targets-components analysis related to the putative human proteins that are principally targeted by catechin. 

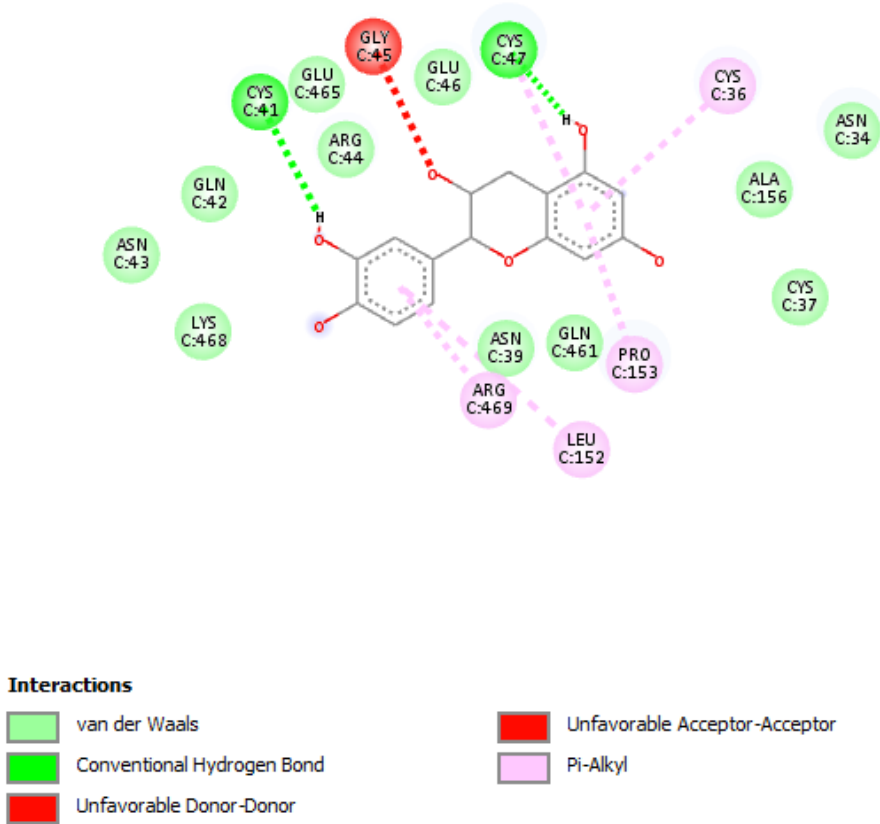

(A)
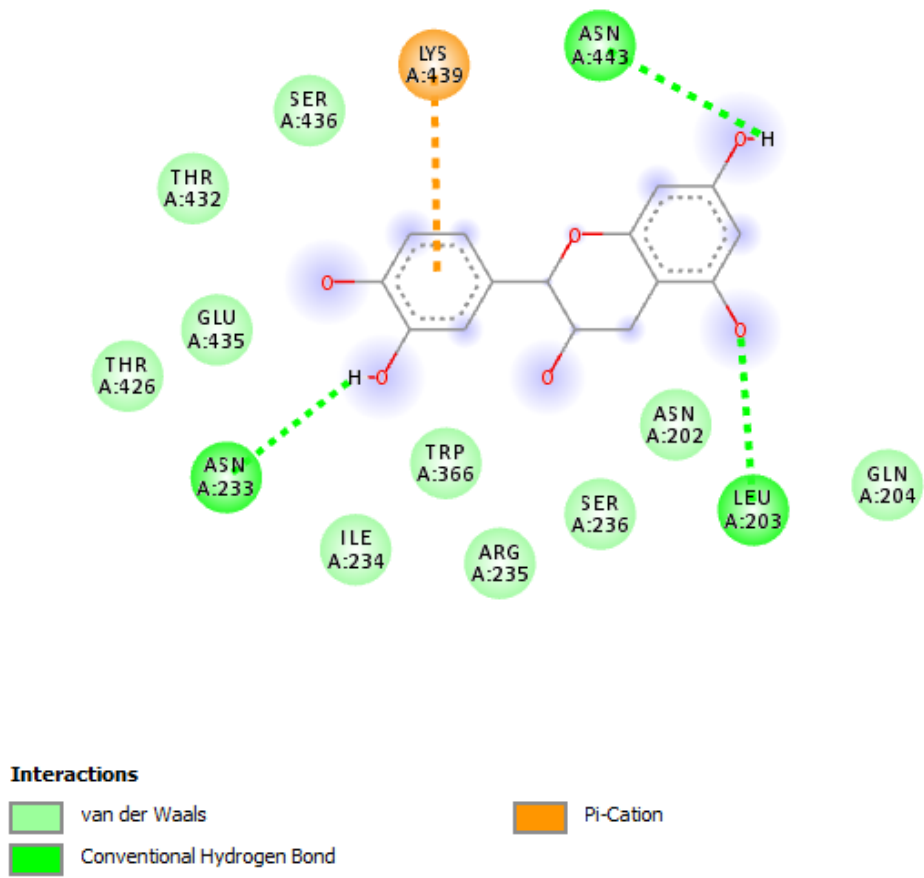

Pi-Cation

(B)

Figure 12. (A) Putative interactions between catechin and human cyclooxygenase-2 (COX-2; PDB: 1CX2). Free energy of binding $(\Delta \mathrm{G})$ and affinity $(\mathrm{Ki})$ are $-9.5 \mathrm{kcal} / \mathrm{mol}$ and $0.1 \mu \mathrm{M}$, respectively; (B) Putative interactions between catechin and human inducible nitric oxide synthase (iNOS; PDB: 1DD7). Free energy of binding $(\Delta \mathrm{G})$ and affinity (Ki) are $-7.5 \mathrm{kcal} / \mathrm{mol}$ and $3.2 \mu \mathrm{M}$, respectively. 


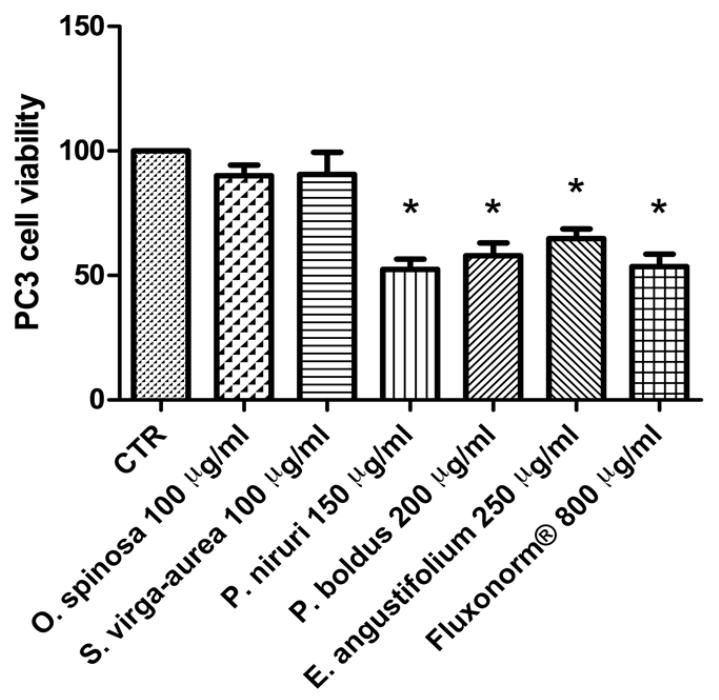

Figure 13. Effect of extracts of Phyllanthus niruri $100 \mu \mathrm{g} / \mathrm{mL}$, Ononis spinosa $100 \mu \mathrm{g} / \mathrm{mL}$, Solidago virga-aurea $150 \mu \mathrm{g} / \mathrm{mL}$, Peumus boldus $200 \mu \mathrm{g} / \mathrm{mL}$, and Epilobium angustifolium $250 \mu \mathrm{g} / \mathrm{mL}$ water extracts and Fluxonorm ${ }^{\circledR} 800 \mu \mathrm{g} / \mathrm{mL}$ on prostate cancer PC3 cell line viability. ANOVA, $p<0.01$, post-hoc ${ }^{*} p<0.05$ vs. CTR group.

\section{Conclusions}

The results of the present study showed moderate antimicrobial and anti-inflammatory effects induced by water extracts of S. virga-aurea, P. boldus, E. angustifolium, P. niruri, and $O$. spinosa, that could be related, at least partially, to the phenolic composition of the phytocomplex. Future phytochemical investigations may further unravel the relationships between extract composition and bio-pharmacological effects.

Author Contributions: Conceptualization, M.P. (Massimiliano Petrucci), P.A., G.O., and C.F.; methodology, P.A., L.M., G.O. and G.Z.; software, C.F.; validation, P.A., G.O., L.M., G.Z. and C.F.; formal analysis, C.F.; investigation, G.A.F., A.C., L.R., S.L., R.V., M.D.M., F.B., M.P. (Matteo Politi) and G.A.; resources, G.O. and C.F.; data curation, P.A., G.Z. and L.M.; writing-original draft preparation, C.F. and P.A.; writing-review and editing, C.F., L.M. and G.O.; visualization, R.V. and L.B.; supervision, L.B.; project administration, P.A., C.F. and G.O.; funding acquisition, M.P. (Massimiliano Petrucci). All authors have read and agreed to the published version of the manuscript.

Funding: This work was supported by OMEGA PHARMA Srl (Cantù, Italy).

Acknowledgments: The authors would like to thank Lucio Boschi (Veridia Italia Srl) for technical assistance during the study that was conducted within a joint project between the Department of Pharmacy of "G. d'Annunzio" University and Veridia Srl (Research Program 2020-2023). Study Coordinators were Giustino Orlando, Luigi Menghini, and Claudio Ferrante.

Conflicts of Interest: The study was supported by OMEGA PHARMA Srl.

\section{References}

1. Steenkamp, V.; Gouws, M.C.; Gulumian, M.; Elgorashi, E.E.; van Staden, J. Studies on antibacterial, anti-inflammatory and antioxidant activity of herbal remedies used in the treatment of benign prostatic hyperplasia and prostatitis. J. Ethnopharmacol. 2006, 103, 71-75. [CrossRef]

2. Delcaru, C.; Podgoreanu, P.; Alexandru, I.; Popescu, N.; Măruţescu, L.; Bleotu, C.; Mogoşanu, G.D.; Chifiriuc, M.C.; Gluck, M.; Lazăr, V. Antibiotic Resistance and Virulence Phenotypes of Recent Bacterial Strains Isolated from Urinary Tract Infections in Elderly Patients with Prostatic Disease. Pathogens 2017, 6, 22. [CrossRef]

3. Delcaru, C.; Alexandru, I.; Podgoreanu, P.; Grosu, M.; Stavropoulos, E.; Chifiriuc, M.C.; Lazar, V. Microbial Biofilms in Urinary Tract Infections and Prostatitis: Etiology, Pathogenicity, and Combating strategies. Pathogens 2016, 5, 65. [CrossRef] [PubMed] 
4. Marzano, R.; Dinelli, N.; Ales, V.; Bertozzi, M.A. Effectiveness on urinary symptoms and erectile function of Prostamev Plus@vs only extract Serenoa repens. Arch. Ital. Urol. Androl. 2015, 87, 25-27. [CrossRef]

5. Bjorling, D.E.; Wang, Z.Y.; Bushman, W. Models of inflammation of the lower urinary tract. Neurourol. Urodyn. 2011, 30, 673-682. [CrossRef]

6. Nickel, J.C. Alpha-blockers for the treatment of prostatitis-like syndromes. Rev. Urol. 2006, 8 (Suppl. S4), S26-S34. [PubMed]

7. Stamatiou, K.; Pierris, N. Serenoa repens extract additionally to quinolones in the treatment of chronic bacterial prostatitis. The preliminary results of a long term observational study. Arch. Ital. Urol. Androl. 2013, 85, 190-196. [CrossRef] [PubMed]

8. Cai, T.; Morgia, G.; Carrieri, G.; Terrone, C.; Imbimbo, C.; Verze, P.; Mirone, V. IDIProst ${ }^{\circledR}$ Gold Study Group. An improvement in sexual function is related to better quality of life, regardless of urinary function improvement: Results from the IDIProst ${ }^{\circledR}$ Gold Study. Arch. Ital. Urol. Androl. 2013, 85, 184-189. [CrossRef] [PubMed]

9. Wang, M.; Ma, H.L.; Liu, B.; Wang, H.B.; Xie, H.; Li, R.D.; Wang, J.F. Pinus massoniana bark extract protects against oxidative damage in L-02 hepatic cells and mice. Am. J. Chin. Med. 2010, 38, 909-919. [CrossRef] [PubMed]

10. Iglesias-Gato, D.; Carsten, T.; Vesterlund, M.; Pousette, A.; Schoop, R.; Norstedt, G. Androgen-independent effects of Serenoa repens extract (Prostasan ${ }^{\circledR}$ ) on prostatic epithelial cell proliferation and inflammation. Phytother. Res. 2012, 26, 259-264. [CrossRef]

11. Chiavaroli, A.; Recinella, L.; Ferrante, C.; Locatelli, M.; Carradori, S.; Macchione, N.; Zengin, G.; Leporini, L.; Leone, S.; Martinotti, S.; et al. Crocus sativus, Serenoa repens and Pinus massoniana extracts modulate inflammatory response in isolated rat prostate challenged with LPS. J. Biol. Regul. Homeost. Agents 2017, 31, 531-541. [PubMed]

12. Menghini, L.; Ferrante, C.; Leporini, L.; Recinella, L.; Chiavaroli, A.; Leone, S.; Pintore, G.; Vacca, M.; Orlando, G.; Brunetti, L. A natural formula containing lactoferrin, Equisetum arvensis, soy isoflavones and vitamin D3 modulates bone remodeling and inflammatory markers in young and aged rats. J. Biol. Regul. Homeost. Agents 2016, 30, 985-996.

13. Tabatabaei-Malazy, O.; Larijani, B.; Abdollahi, M. Targeting metabolic disorders by natural products. J. Diabetes Metab. Disord. 2015, 14, 57. [CrossRef]

14. Jones, W.P.; Chin, Y.W.; Kinghorn, A.D. The role of pharmacognosy in modern medicine and pharmacy. Curr. Drug Targets. 2006, 7, 247-264. [CrossRef]

15. Chichiriccò, G.; Ferrante, C.; Menghini, L.; Recinella, L.; Leone, S.; Chiavaroli, A.; Brunetti, L.; Di Simone, S.; Ronci, M.; Piccone, P.; et al. Crocus sativus by-products as sources of bioactive extracts: Pharmacological and toxicological focus on anthers. Food Chem. Toxicol. 2019, 126, 7-14. [CrossRef]

16. Ferrante, C.; Recinella, L.; Ronci, M.; Menghini, L.; Brunetti, L.; Chiavaroli, A.; Leone, S.; Di Iorio, L.; Carradori, S.; Tirillini, B.; et al. Multiple pharmacognostic characterization on hemp commercial cultivars: Focus on inflorescence water extract activity. Food Chem. Toxicol. 2019, 125, 452-461. [CrossRef] [PubMed]

17. Tang, Y.Q.; Jaganath, I.; Manikam, R.; Sekaran, S.D. Phyllanthus Suppresses Prostate Cancer Cell, PC-3, Proliferation and Induces Apoptosis through Multiple Signalling Pathways (MAPKs, PI3K/Akt, NFkB, and Hypoxia). Evid. Based. Complement. Alternat. Med. 2013, 2013, 609581. [CrossRef]

18. Gerhardt, D.; Bertola, G.; Dietrich, F.; Figueiró, F.; Zanotto-Filho, A.; Moreira Fonseca, J.C.; Morrone, F.B.; Barrios, C.H.; Battastini, A.M.; Salbego, C.G. Boldine induces cell cycle arrest and apoptosis in T24 human bladder cancer cell line via regulation of ERK, AKT, and GSK-3ß. Urol. Oncol. 2014, 32, 36.e1-36.e9. [CrossRef]

19. Gampe, N.; Darcsi, A.; Kursinszki, L.; Béni, S. Separation and characterization of homopipecolic acid isoflavonoid ester derivatives isolated from Ononis spinosa L. root. J. Chromatogr. B Analyt. Technol. Biomed. Life Sci. 2018, 1091, 21-28. [CrossRef]

20. Choi, S.Z.; Choi, S.U.; Lee, K.R. Phytochemical constituents of the aerial parts from Solidago virga-aurea var. gigantea. Arch. Pharm. Res. 2004, 27, 164-168. [CrossRef]

21. Choi, S.Z.; Choi, S.U.; Bae, S.Y.; Pyo, S.; Lee, K.R. Immunobiological [correction of Immunobioloical] activity of a new benzyl benzoate from the aerial parts of Solidago virga-aurea var. gigantea. Arch. Pharm. Res. 2005, 28, 49-54. [CrossRef] [PubMed] 
22. Deng, L.; Zong, W.; Tao, X.; Liu, S.; Feng, Z.; Lin, Y.; Liao, Z.; Chen, M. Evaluation of the therapeutic effect against benign prostatic hyperplasia and the active constituents from Epilobium angustifolium L. J. Ethnopharmacol. 2019, 232, 1-10. [CrossRef] [PubMed]

23. Schepetkin, I.A.; Ramstead, A.G.; Kirpotina, L.N.; Voyich, J.M.; Jutila, M.A.; Quinn, M.T. Therapeutic Potential of Polyphenols from Epilobium Angustifolium (Fireweed). Phytother. Res. 2016, 30, 1287-1297. [CrossRef]

24. Locatelli, M.; Ferrante, C.; Carradori, S.; Secci, D.; Leporini, L.; Chiavaroli, A.; Leone, S.; Recinella, L.; Orlando, G.; Martinotti, S.; et al. Optimization of Aqueous Extraction and Biological Activity of Harpagophytum procumbens Root on Ex Vivo Rat Colon Inflammatory Model. Phytother. Res. 2017, 31, 937-944. [CrossRef]

25. Recinella, L.; Chiavaroli, A.; Ronci, M.; Menghini, L.; Brunetti, L.; Leone, S.; Tirillini, B.; Angelini, P.; Covino, S.; Venanzoni, R.; et al. Multidirectional Pharma-Toxicological Study on Harpagophytum procumbens DC. ex Meisn.: An IBD-Focused Investigation. Antioxidants (Basel) 2020, 9, 168. [CrossRef]

26. Mishra, P.P.; Prakash, V.; Singh, K.; Mog, H.; Agarwal, S. Bacteriological Profile of Isolates From Urine Samples in Patients of Benign Prostatic Hyperplasia and or Prostatitis Showing Lower Urinary Tract Symptoms. J. Clin. Diagn. Res. 2016, 10, 16-18. [CrossRef]

27. Jain, S.; Samal, A.G.; Das, B.; Pradhan, B.; Sahu, N.; Mohapatra, D.; Behera, P.K.; Satpathi, P.S.; Mohanty, A.K.; Satpathi, S.; et al. Escherichia coli, a common constituent of benign prostate hyperplasia-associated microbiota induces inflammation and DNA damage in prostate epithelial cells. Prostate 2020. [CrossRef]

28. Odabasi, Z.; Mert, A. Candida urinary tract infections in adults. World J. Urol. 2019. [CrossRef] [PubMed]

29. Irimie, M.; Tătaru, A.; Oantă, A.; Moga, M. In vitro susceptibility of dermatophytes isolated from patients with end-stage renal disease: A case-control study. Mycoses 2014, 57, 129-134. [CrossRef]

30. Magagnin, C.M.; Stopiglia, C.D.; Vieira, F.J.; Heidrich, D.; Machado, M.; Vetoratto, G.; Lamb, F.M.; Scroferneker, M.L. Antifungal susceptibility of dermatophytes isolated from patients with chronic renal failure. An. Bras. Dermatol. 2011, 86, 694-701. [CrossRef] [PubMed]

31. Casamiquela, K.M.; Cohen, P.R. Radiation port dermatophytosis: Tinea corporis occurring at the site of irradiated skin. Dermatol. Online J. 2012, 18, 5.

32. Sousa, V.; Luís, Â.; Oleastro, M.; Domingues, F.; Ferreira, S. Polyphenols as resistance modulators in Arcobacter butzleri. Folia Microbiol. (Praha) 2019, 64, 547-554. [CrossRef]

33. Koudoufio, M.; Desjardins, Y.; Feldman, F.; Spahis, S.; Delvin, E.; Levy, E. Insight into Polyphenol and Gut Microbiota Crosstalk: Are Their Metabolites the Key to Understand Protective Effects against Metabolic Disorders? Antioxidants (Basel) 2020, 9, 982. [CrossRef] [PubMed]

34. Rodríguez-Delgado, M.A.; Malovaná, S.; Pérez, J.P.; Borges, T.; García Montelongo, F.J. Separation of phenolic compounds by high-performance liquid chromatography with absorbance and fluorimetric detection. J. Chromatogr. A 2001, 912, 249-257. [CrossRef]

35. Orlando, G.; Leone, S.; Ferrante, C.; Chiavaroli, A.; Mollica, A.; Stefanucci, A.; Macedonio, G.; Dimmito, M.P.; Leporini, L.; Menghini, L.; et al. Effects of Kisspeptin-10 on Hypothalamic Neuropeptides and Neurotransmitters Involved in Appetite Control. Molecules 2018, 23, 3071. [CrossRef]

36. Chiavaroli, A.; Brunetti, L.; Orlando, G.; Recinella, L.; Ferrante, C.; Leone, S.; Di Michele, P.; Di Nisio, C.; Vacca, M. Resveratrol inhibits isoprostane production in young and aged rat brain. J. Biol. Regul. Homeost. Agents 2010, 24, 441-446.

37. Ferrante, C.; Angelini, P.; Venanzoni, R.; Angeles Flores, G.; Tirillini, B.; Recinella, L.; Chiavaroli., A.; Brunetti, L.; Leone, S.; Di Simone, S.C.; et al. Antimicrobial, Antioxidant, and Antiproliferative Effects of Coronilla minima: An Unexplored Botanical Species. Antibiotics (Basel) 2020, 9, 611. [CrossRef]

38. Angelini, P.; Venanzoni, R.; Angeles Flores, G.; Tirillini, B.; Orlando, G.; Recinella, L.; Chiavaroli, A.; Brunetti, L.; Leone, S.; Di Simone, S.C.; et al. Evaluation of Antioxidant, Antimicrobial and Tyrosinase Inhibitory Activities of Extracts from Trichophyton goniospermum, an Edible Wild Mushroom. Antibiotics (Basel) 2020, 9, 513. [CrossRef]

39. Gu, L.; Lu, J.; Li, Q.; Wu, N.; Zhang, L.; Li, H.; Xing, W.; Zhang, X. A network-based analysis of key pharmacological pathways of Andrographis paniculata acting on Alzheimer's disease and experimental validation. J. Ethnopharmacol. 2019, 251, 112488. [CrossRef] 
40. Daglia, M.; Di Lorenzo, A.; Nabavi, S.F.; Talas, Z.S.; Nabavi, S.M. Polyphenols: Well beyond the antioxidant capacity: Gallic acid and related compounds as neuroprotective agents: You are what you eat! Curr. Pharm. Biotechnol. 2014, 15, 362-372. [CrossRef] [PubMed]

41. Özdemir, Z.; Utku, S.; Mathew, B.; Carradori, S.; Orlando, G.; Di Simone, S.; Alagöz, M.A.; Özçelik, A.B.; Uysal, M.; Ferrante, C. Synthesis and biological evaluation of new $3(2 \mathrm{H})$-pyridazinone derivatives as non-toxic anti-proliferative compounds against human colon carcinoma HCT116 cells. J. Enzym. Inhib. Med. Chem. 2020, 35, 1100-1109. [CrossRef]

42. Huang, E.; Yang, X.; Zhang, L.; Moon, S.H.; Yousef, A.E. New Paenibacillus strain produces a family of linear and cyclic antimicrobial lipopeptides: Cyclization is not essential for their antimicrobial activity. FEMS Microbiol. Lett. 2017, 364. [CrossRef]

43. Guo, Y.; Huang, E.; Yang, X.; Zhang, L.; Yousef, A.E.; Zhong, J. Isolation and characterization of a Bacillus atrophaeus strain and its potential use in food preservation. Food Control. 2016, 60, 511-518. [CrossRef]

44. Yang, X.; Huang, E.; Yuan, C.; Zhang, L.; Yousef, A.E. Isolation and Structural Elucidation of Brevibacillin, an Antimicrobial Lipopeptide from Brevibacillus laterosporus That Combats Drug-Resistant Gram-Positive Bacteria. Appl. Environ. Microbiol. 2016, 82, 2763-2772. [CrossRef]

45. Orlando, G.; Ferrante, C.; Zengin, G.; Sinan, K.I.; Bene, K.; Diuzheva, A.; Jekő, J.; Cziáky, Z.; Simone, S.D.; Recinella, L.; et al. Qualitative Chemical Characterization and Multidirectional Biological Investigation of Leaves and Bark Extracts of Anogeissus leiocarpus (DC.) Guill. \& Perr. (Combretaceae). Antioxidants (Basel) 2019, 8, 343. [CrossRef]

46. di Giacomo, V.; Ferrante, C.; Ronci, M.; Cataldi, A.; Di Valerio, V.; Rapino, M.; Recinella, L.; Chiavaroli, A.; Leone, S.; Vladimir-Knežević, S.; et al. Multiple pharmacological and toxicological investigations on Tanacetum parthenium and Salix alba extracts: Focus on potential application as anti-migraine agents. Food Chem. Toxicol. 2019, 133, 110783. [CrossRef]

47. Abnosi, M.H.; Yari, S. The toxic effect of gallic acid on biochemical factors, viability and proliferation of rat bone marrow mesenchymal stem cells was compensated by boric acid. J. Trace Elem. Med. Biol. 2018, 48, 246-253. [CrossRef]

48. Locatelli, M.; Macchione, N.; Ferrante, C.; Chiavaroli, A.; Recinella, L.; Carradori, S.; Zengin, G.; Cesa, S.; Leporini, L.; Leone, S.; et al. Graminex Pollen: Phenolic Pattern, Colorimetric Analysis and Protective Effects in Immortalized Prostate Cells (PC3) and Rat Prostate Challenged with LPS. Molecules 2018, 23, 1145. [CrossRef]

49. Koeberle, A.; Werz, O. Inhibitors of the microsomal prostaglandin E(2) synthase-1 as alternative to non steroidal anti-inflammatory drugs (NSAIDs)-a critical review. Curr. Med. Chem. 2009, 16, 4274-4296. [CrossRef] [PubMed]

50. Brunetti, L.; Leone, S.; Chiavaroli, A.; Orlando, G.; Recinella, L.; Ferrante, C.; Di Nisio, C.; Verratti, V.; Vacca, M. Cafeteria diet increases prostaglandin E2 levels in rat prostate, kidney and testis. Int. J. Immunopathol. Pharmacol. 2010, 23, 1073-1078. [CrossRef]

51. Verratti, V.; Brunetti, L.; Ferrante, C.; Orlando, G.; Recinella, L.; Chiavaroli, A.; Leone, S.; Wang, R.; Berardinelli, F. Physiological and pathological levels of prostaglandin E2 in renal parenchyma and neoplastic renal tissue. Prostaglandins Other Lipid Mediat. 2019, 141, 11-13. [CrossRef] [PubMed]

52. Uttara, B.; Singh, A.V.; Zamboni, P.; Mahajan, R.T. Oxidative stress and neurodegenerative diseases: A review of upstream and downstream antioxidant therapeutic options. Curr. Neuropharmacol. 2009, 7, 65-74. [CrossRef] [PubMed]

53. Praticò, D. Alzheimer's disease and oxygen radicals: New insights. Biochem. Pharmacol. 2002, 63, 563-567. [CrossRef]

54. Verratti, V.; Brunetti, L.; Tenaglia, R.; Chiavaroli, A.; Ferrante, C.; Leone, S.; Orlando, G.; Berardinelli, F.; Di Giulio, C.; Vacca, M. Physiological analysis of 8-ISO-PGF2 alpha: A homeostatic agent in superficial bladder cancer. J. Biol. Regul. Homeost. Agents 2011, 25, 71-76.

55. Al-Sayed, E.; Abdel-Daim, M.M. Analgesic and anti-inflammatory activities of epicatechin gallate from Bauhinia hookeri. Drug Dev. Res. 2018, 79, 157-164. [CrossRef]

56. Micali, S.; Territo, A.; Pirola, G.M.; Ferrari, N.; Sighinolfi, M.C.; Martorana, E.; Navarra, M.; Bianchi, G. Effect of green tea catechins in patients with high-grade prostatic intraepithelial neoplasia: Results of a short-term double-blind placebo controlled phase II clinical trial. Arch. Ital. Urol. Androl. 2017, 89, 197-202. [CrossRef] 
57. Hayakawa, S.; Ohishi, T.; Miyoshi, N.; Oishi, Y.; Nakamura, Y.; Isemura, M. Anti-Cancer Effects of Green Tea Epigallocatchin-3-Gallate and Coffee Chlorogenic Acid. Molecules 2020, 25, 4553. [CrossRef]

58. Reddivari, L.; Vanamala, J.; Safe, S.H.; Miller, J.C., Jr. The bioactive compounds alpha-chaconine and gallic acid in potato extracts decrease survival and induce apoptosis in LNCaP and PC3 prostate cancer cells. Nutr. Cancer 2010, 62, 601-610. [CrossRef]

59. Afsar, T.; Trembley, J.H.; Salomon, C.E.; Razak, S.; Khan, M.R.; Ahmed, K. Growth inhibition and apoptosis in cancer cells induced by polyphenolic compounds of Acacia hydaspica: Involvement of multiple signal transduction pathways. Sci. Rep. 2016, 6, 23077. [CrossRef]

Publisher's Note: MDPI stays neutral with regard to jurisdictional claims in published maps and institutional affiliations.

(C) 2020 by the authors. Licensee MDPI, Basel, Switzerland. This article is an open access article distributed under the terms and conditions of the Creative Commons Attribution (CC BY) license (http://creativecommons.org/licenses/by/4.0/). 